\title{
Göçmen Ekonomisi: Hollanda Üzerine Karşılaştırmalı Bir Analiz
}

\section{Yazar}

Doç. Dr. Ömer Tarık GENÇOSMANOĞLU 


\section{(C) Copyright 2021}

Bu kitabın, basım, yayın ve satı̧s haklam Akademisyen Kitabevi A.Ş.'ye aittir. Anılan kuruluşun izni alınmadan kitabın tümü ya da bölümleri mekanik, elektronik, fotokopi, manyetik kağıt ve/veya başka yöntemlerle çoğaltılamaz, basılamaz, dağıtılamaz. Tablo, şekil ve grafikler izin alınmadan, ticari amaçh kullamılamaz. Bu kitap T.C. Kültür Bakanlğ̆ bandrolü ile satılmaktadır.

\section{ISBN}

978-625-7496-18-6

\section{Kitap Adı}

Göçmen Ekonomisi: Hollanda Üzerine Karşılaştırmalı Bir Analiz

\section{Yazar}

Ömer Tarık GENÇOSMANOĞLU

ORCID iD: 0000-0003-3979-6387

\section{Yayın Koordinatörü \\ Yasin DİLMEN}

Sayfa ve Kapak Tasarımı

Akademisyen Dizgi Ünitesi

Yayıncı Sertifika No

47518

Baskı ve Cilt

Vadi Matbaacılık

Bisac Code

BUS068000

DOI

10.37609/akya.853

\section{GENEL DAĞITIM}

\section{Akademisyen Kitabevi A.Ş.}

Halk Sokak 5 / A

Yenişehir / Ankara

Tel: o312 4311633

siparis@akademisyen.com 


\section{ÖNSÖZ}

\section{KITABIN AMACI}

Uluslararası göçmenler bir yandan göç ettikleri ülkeleri ekonomik, sosyal, politik ve kültürel yönlerden etkilerken, diğer yandan kendileri ve sonraki nesilleri yaşadıkları ülkelerdeki koşulların etkisi altında kalmaktadır. Entegrasyon olarak nitelendirilen bu etkiler göç alan ülkeler tarafından giderek daha fazla önemsenmekte ve düzenli olarak izlenmektedir. Bununla birlikte, Birleşmiş Milletlere bağlı Uluslararası Göç Örgütü (International Organization for Migration veya IOM)'a göre göçmenlerin uyumu hakkında küresel boyutta sağlıklı bilgi, çalışma ve değerlendirmelere ihtiyaç bulunmaktadır.

Bu çalışmada, göçmenlerin yıllar ve kuşaklar itibariyle ekonomi alanında sağladığı uyum düzeyi Hollanda özelinde karşılaştırmalı bir biçimde ele alınmıştır. Kitapta Hollanda’ya gelen göçmenlerin işgücü olarak emek piyasasındaki, girişimci ve işveren olarak iş dünyasındaki ve ticaret erbabı olarak da diş ticaretteki yerleri tanımlayıcı istatistikler kullanılarak analiz edilmiştir. Analizlerde ana göçmen grupları hem birbirleriyle hem de Hollandalılarla ayrı ayrı karşılaştırılmıştır. Bu bakımdan, çalışmanın göçmenlerin Hollanda ekonomisindeki rolü konusunda hazırlanan nadir eserlerden birisi olduğuna inanıyorum. Kitap, 2017-2021 yılları arasında araştırmacı olarak Erasmus Üniversitesinde (Hollanda) "uluslararası ticaret ve göç arasındaki ilişki” hakkında yaptığım araştırmalarda derlenen detaylı verilere dayanmaktadır.

\section{NEDEN HOLLANDA?}

Hollanda coğrafi olarak küçük bir ülke olmakla beraber gayrı safi yurt içi hâsıla ve dış ticaret hacmi bakımından dünyada önde gelen ülkeler arasındadır. Ayrıca ülke büyük bir göçmen nüfusa sahiptir. Günümüzde yaklaşık dört milyon göçmenin yaşadığ 1 ülkede her dört kişiden neredeyse birisi göçmendir. Köken olarak da dünyanın pek çok ülkesinden göçmen barındıran Hollanda'da göçmenlere yönelik kapsamlı verilerin bulunması, göçmenlerin Hollanda ekonomisindeki yerine ilişkin karşılaştırmalı analizler yapılmasına imkân sağlamaktadır.

Hollanda, Türk göçmenler için ayrı bir önem taşımaktadır. Yurt dışında Türklerin en kalabalık olduğu ülke belki Hollanda değildir; ancak ülke nüfusuna göre 
Türklerin en yoğun yaşadığı yerlerin başında gelmektedir. Türkiye ile Hollanda arasındaki göç ilişkileri çok eski tarihlere dayanmakla birlikte, resmi kurumların, sivil toplum kuruluşlarının ve daha da önemlisi Hollandalı Türklerin elinde sağlıklı ve referans alınabilecek sağlıklı, kapsamlı ve derli toplu veriler bulunmamaktadır. Bu kitabın, böyle bir eksikliğin giderilmesine ayrıca büyük katkı sağlayacağ11 umuyorum.

\section{HEDEF KITLESi}

Kitap birçok kesime ve alana hitap etmektedir. Hollanda'daki göçmen gruplarının özelliklerini, bunların grup-içi ve gruplar arası ekonomik ilişkilerini daha iyi anlamak isteyen ekonomistler, siyaset bilimcileri, sosyologlar ve karar alıcılar için bilhassa önemli bir kaynak olabileceğini düşünüyorum.

Göç araştırmalarına yönelik artan bir ilginin varlığı tartışılmazdır. Nitekim Uluslararası Göç Örgütü’nün hazırladı̆̆ı son “Dünya Göç Raporu” uzun bir süreden bu yana göç araştırmalarına yönelik çalışmaların artış eğilimine dikkat çekmiştir. Rapor ayrıca, hükümetlerarası kuruluşların göç meseleleri hakkında çok sayıda küresel rapora temel teşkil eden kapsamlı faaliyetlerine atıf yapmıştır. Bu itibarla, ayrıntılı verilerle desteklenen çıkarımlar sunan bu çalışmanın gerek akademi camiası, gerek ulusal ve hükümetlerarası kuruluşlar tarafından yürütülen çalışmalara da mütevazı katkılarda bulunmasını bekliyorum.

Bunlara ilave olarak, kitabın Hollanda'daki göçmen gruplarının gelişimi hakkında çalışmalar yapan sivil toplum kuruluşlarının ve bizzat göçmenlerin de ilgisini çekeceği tahmin ediyorum. Ülkeye geldikten sonra geçirdikleri sosyoekonomik değişimleri irdeleyen kısımları özellikle göçmen topluluklar merakla okuyacaklardır.

\section{ÇALIȘMANIN PLANI}

Kitap altı bölümden oluşmaktadır. Kitapta öncelikle göç ve göçmenlerle ilgili temel kavramlar üzerinde durulmakta, ayrıca dünyada ve Hollanda'da göçmen hareketlerinin genel görünümü ele alınmaktadır.

İkinci bölümde Hollanda'da yaşayan göçmen gruplarının ulusal işgücü piyasasına katılımı birçok yönden değerlendirilmektedir. Örneğin, toplam işgücünün Hollandalı ve göçmen grupları itibariyle dağılımının yanı sıra bu grupların ortalama saatlik ücretleri ve çalışma süreleri arasındaki farklılıklara değinilmektedir. 
Göçmen çalışanların eğitim seviyesi, yaşları, çalıştıkları sektörler ve işyerindeki pozisyonları nesillere ve cinsiyete göre ayrı ayrı ele alınmaktadır. Ayrıca, göçmen işgücünün ülke genelinde iller ve belediyelere göre dağılımına bakılmaktadır.

Üçüncü bölüm, Hollanda’da kendi işini kuran göçmen girişimcilerle ilgilidir. Hollandalı ve göçmen girişimcilerin illere ve belediyelere göre sayıları, elde elde ettikleri kazançları/ciroları, istihdamları ve sektör tercihleri bir arada sunulmaktadır. Ayrıca, göçmenlerin girişimcilik düzeyindeki gelişmeler kuşaklar ve cinsiyet itibariyle ele alınmaktadır.

Dördüncü bölüm, Hollandalılar ve göçmenler tarafından yönetilen firmalara ilişkin geniş ve detaylı bilgiler vermektedir. Bu bölümde göçmen gruplarının kendi aralarında ya da Hollandalılarla kurduğu ortaklıklar hakkında ayrıntılar yer almaktadır. Bu analizde firmaların ciroları, çalışan sayısı, işletme büyüklüğü ve ülkenin idari bölgelerine göre dağılımları ele alınmaktadır. Hollandalı ve göçmen grupları itibariyle işletilen firmalardaki işgücünün etnik kökenlerine göre dağılımları işveren-işçi ilişkisinde göçmenler açısından ilginç sonuçlara işaret etmektedir.

Beşinci bölüm göçmenler tarafından işletilen firmaların dış ticaret faaliyetlerine ayrılmıştır. İhracat ve ithalat yapan firmaların sayılarına ek olarak bunların dış ticaret hacimleri, ciroları ve istihdamı hakkındaki verilere yer verilmektedir. Göçmenlerin orijin ülkeleriyle dış ticaret bağlantısı olup olmadığına ışık tutan veriler de ayrıca sunulmuştur.

Son bölümde, önceki bölümlerde yapılan tespitler topluca değerlendirilerek göçmenlerin Hollanda ekonomisindeki rolü hakkında ortaya çıkan önemli sonuçlar özetlenmektedir.

\section{YAZAR HAKKINDA}

Ömer Tarık Gençosmanoğlu Üniversitelerarası Kurul Başkanlığında Doçent olup, aynı zamanda T.C. Ticaret Bakanlı̆̆ı Ticaret Araştırmaları ve Risk Değerlendirme Genel Müdürlügünde kıdemli uzman olarak çalışmaktadır. Bundan önce kamuda istatistiksel araştırma, uluslararası proje yönetimi, ticaret politikası analizi, Dünya Ticaret Örgütü ve Türkiye-Avrupa Birliği ilişkileri konularında değişik pozisyonlarda görev yapmıştır.

Dünya Ticaret Örgütü Nezdinde Türkiye Daimi Temsilciliğinde 2006 ve 2009 yılları arasında Ticaret Müşaviri olarak çalışan yazar, sorumlu olduğu birçok DTÖ Komitesi'nin yanı sıra Doha Çoktaraflı Ticaret Müzakerelerinde farklı başlıklar 
altında müzakereler yürütmüşsür. 2017 yılında Türkiye’nin Hollanda Ticaret Ataşesi olarak görevlendirilmiş ve bu görevini 2021 yılına kadar sürdürmüştür.

Doçent Gençosmanoğlu Orta Doğu Teknik Üniversitesi Ekonomi bölümü 1993 mezunu olup, ekonomi dalında Illinois Üniversitesinden (Urbana-Champaign, ABD, 2002) ve Ankara Üniversitesinden (2010) birer yüksek lisans derecesi almış; doktorasını ise Hacettepe Üniversitesi Ekomomi Bölümünde yapmıştır (2014). Uluslararası ticaret, Türkiye-Avrupa Birliği ilişkileri ve gümrük konularında lisans ve yüksek lisans dersleri vermektedir.

\section{KITAP HAKKINDA}

Kitap yaklaşık üç yıllık bir çalışmanın ürünü olup büyük ölçüde Hollanda'da hazırlanmıştır. Hazırlık sürecinde en çok verilerin derlenmesi sırasında zorlanılmıştır. Hollanda İstatistik Bürosu (CBS)'nun binlerce satırdan oluşan nüfus, işgücü, dış ticaret ve vergiye ilişkin mikro düzeydeki veriler göçmen istatistikleriyle birleştirilerek milyonlarca satırdan oluşan veri setlerine dönüştürülmüştür. Böylesine büyük veri setlerinden doğru hesaplamalara ve çıkarımlara ulaşılabilmesi için titiz incelemeler yapılması ve verilerin her aşamada teyid edilmesi gerekmiştir. Ayrıca, CBS tarafından hazırlanan mikro veri hizmetlerine ilişkin Flemenkçe olan teknik belgelerin çoğunluğunun tercüme edilmesine ihtiyaç duyulmuştur.

Hollanda'da CBS' in mikro veri hizmetlerine sadece araştırmacılara, veri gizliliğine ilişkin çok sıkı kurallar çerçevesinde, üniversiteler gibi akredite edilmiş kurumlar bünyesinde erişim izni verilmektedir. Bu çalışma da Erasmus Üniversitesinde projelendirilerek CBS’in mikro veri ortamında günler süren mesainin sonucunda ortaya çıkmıştır. Bildiğim kadarıyla böyle bir çalışma Türklerin önemli bir göçmen grubu olduğu Avrupa ülkelerinde ilk kez yapılmıştır. Kaldı ki diğer göçmen gruplarına dair benzer bir çalışmaya da rastlanmamıştır. Bir çok yerde belirli göçmen gruplarını spesifik konularda ya da zaman diliminlerinde inceleyen kısmi çalışmalar veya raporlar bulunmakla birlikte, mikro verilere dayanan bu kadar kapsayıcı karşılaştırmalı bir analiz henüz yoktur. Nitekim literatüre çok az atıf yapan bu çalışma birinci el bir çalışma olarak kabul edilmelidir.

Göçmenlere yönelik veriler sözel olarak ve grafiklerle sunulmakla beraber, gerektiğinde kullanılabilmesi amacıyla önemli olan veri setleri kitabın sonuna eklenmiştir. İlerleyen bölümlerde görüleceği üzere, akademik standartlara uygun hazırlanmaya gayret edilen çalışmada sadece olgu (fact) analiziyle sınırlı kalınmasına özen gösterilmiştir. 
Kitabın orjinali İngilizce olarak hazırlanmış, ancak hem İngilizce hem Türkçe yayınlanmasının daha yararlı olacağı düşünülmüştür. İngilizce orjinaline birebir sadık kalınan Türkçe versiyonu Hollandalı Türklerin ve göçmenlerle ilgili araştırma yapan çevrelerin kolay erişimine yöneliktir. Kitabın verileri ve sonuçları sosyolojik, kültürel ve politik sahalarda kullanılabilecek nitelikte olmakla birlikte, bu çalışmadaki analizler ekonomi ve ticaret boyutuyla sınırlı tutulmuştur.

Bu çalışmadaki sonuçlar Hollanda İstatistik Bürosu (CBS)'nun kamuoyuna açık olmayan mikro verilerini kullanarak yaptı̆̆ım hesaplamalarına dayanmaktadır ${ }^{1}$. Burada sunulan sonuçlar ve görüşler Türk veya Hollandalı makamların görüşlerini yansıtmamaktadır. Böyle detaylı bir çalışmanın muhtemel hataları şahsıma aittir.

The results in this paper are based on calculations by the author using non-public microdata from Statistics Netherlands. 
- 


\section{IÇINDEKILER}

\section{BÖLÜM}

Dünyada ve Hollanda'da Göçmenler...................................................................1

1. Uluslararası Göç ve Göçmen Tanımı.............................................................................. 1

1.1. Uluslararası Göçün Özellikleri ............................................................................. 1

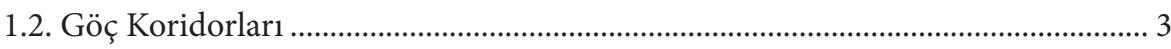

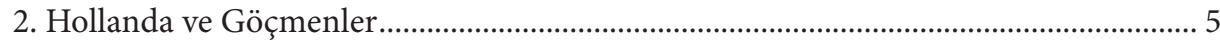

2.1. Göçmenlerin Kökeni..................................................................................... 9

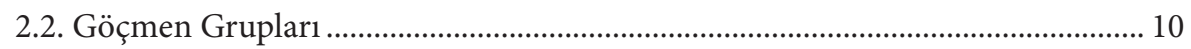

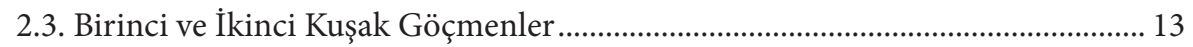

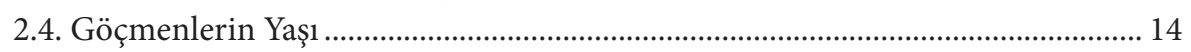

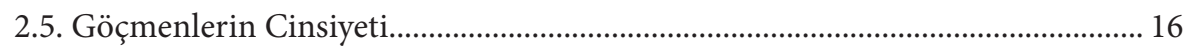

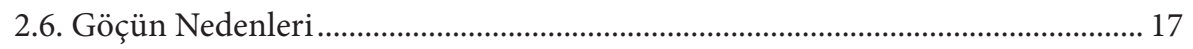

2.7. Göçmen Politikas1 ........................................................................................................... 19

\section{BÖLÜM}

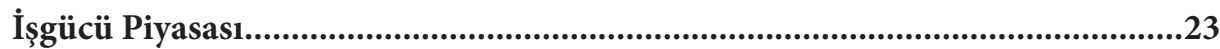

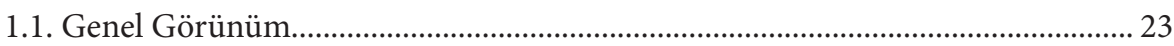

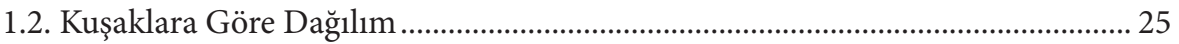

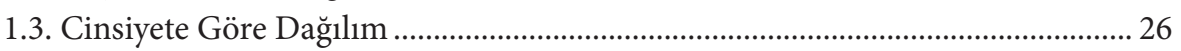

1.4. Göçmen Gruplarının Yaşı ............................................................................................... 27

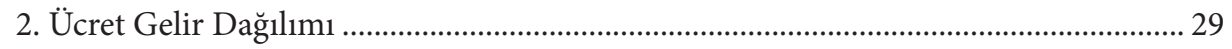

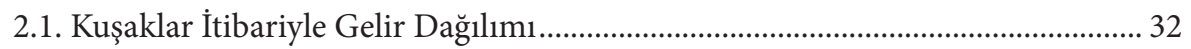

2.2. Ücret Geliri ve Çalışma Süreleri ................................................................................ 34

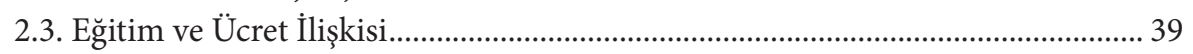

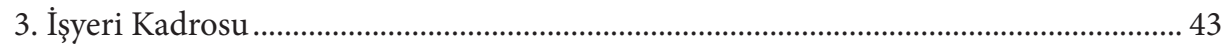

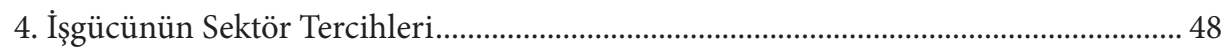

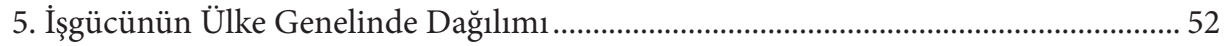

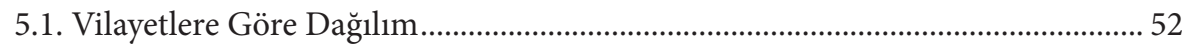

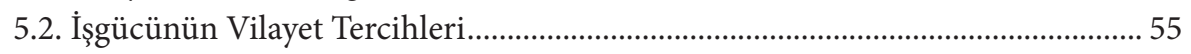

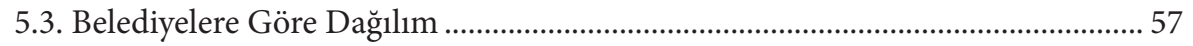

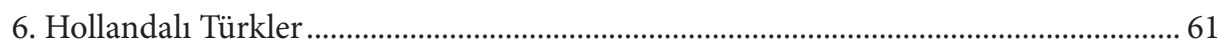

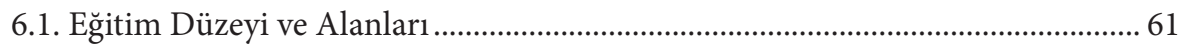

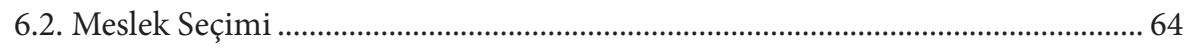

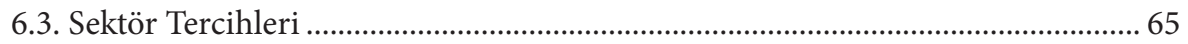




\section{BÖLÜM}

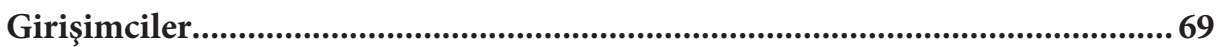

1. Hollandalı ve Göçmen Girişimciler..............................................................................69

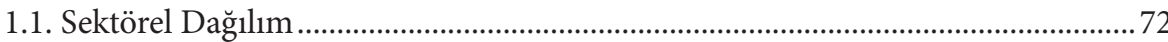

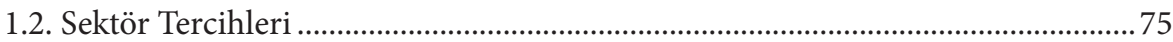

1.3. Girişimci Kuşaklar ve Cinsiyet .................................................................................... 78

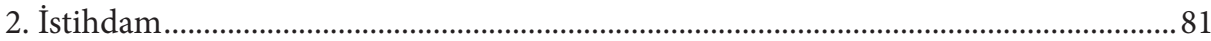

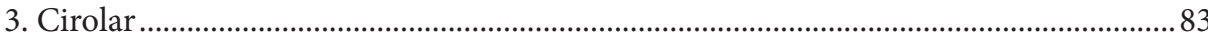

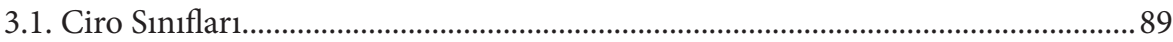

4. Girişimcilerin Hollanda Genelinde Dağılımı............................................................ 91

4.1. Vilayetlerdeki Dağılım............................................................................................... 91

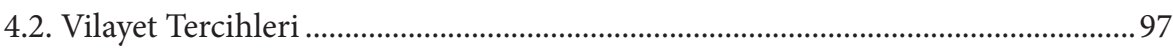

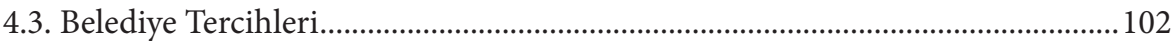

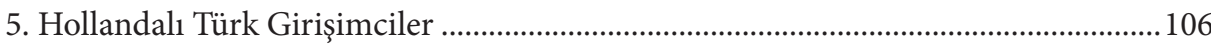

\section{BÖLÜM}

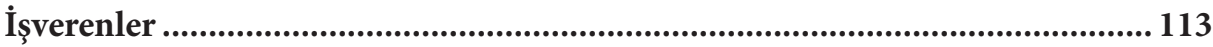

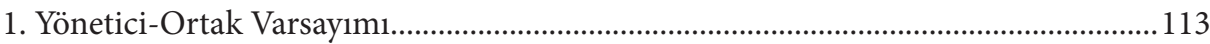

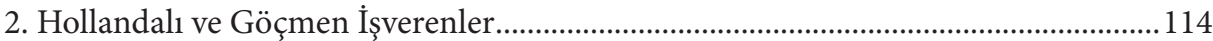

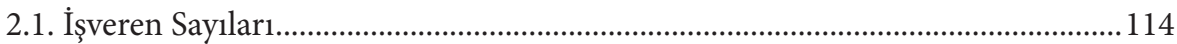

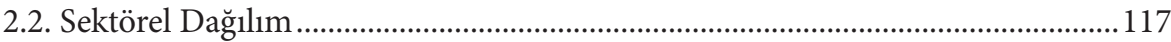

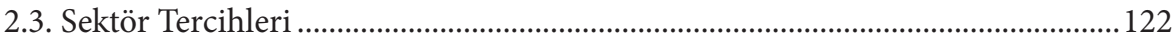

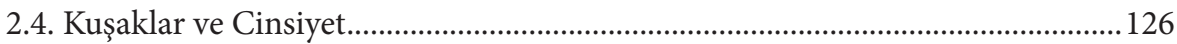

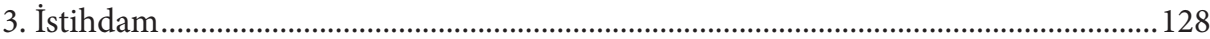

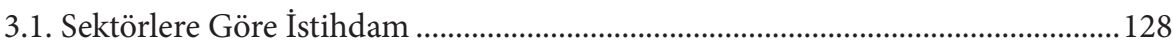

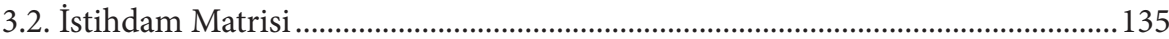

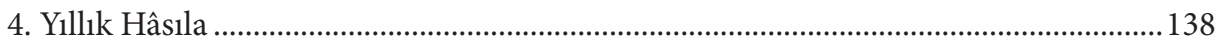

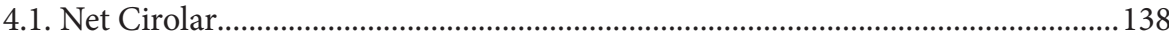

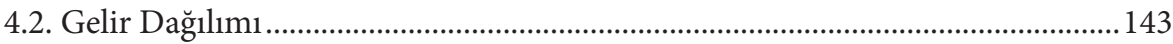

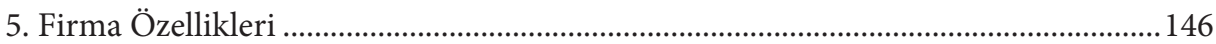

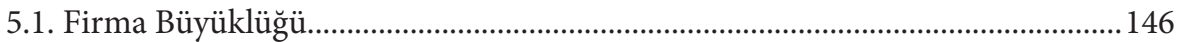

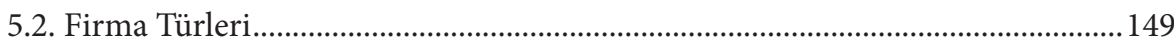

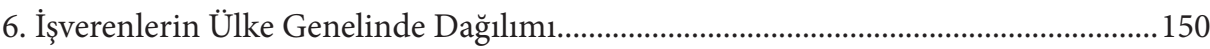

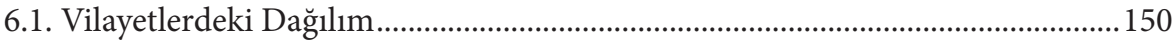

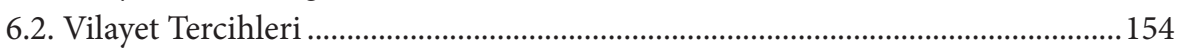

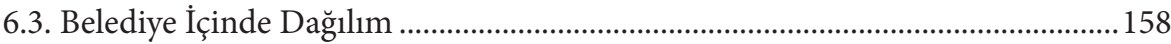

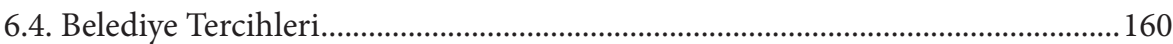

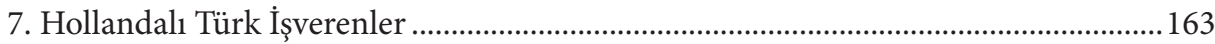

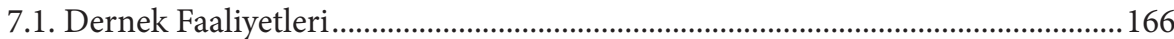




\section{BÖLÜM}

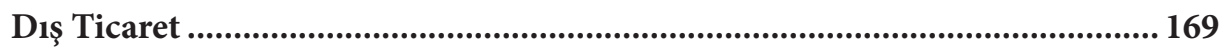

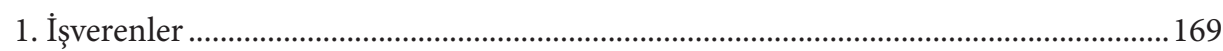

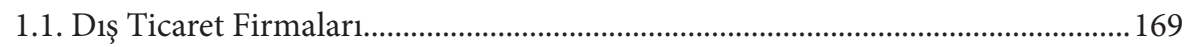

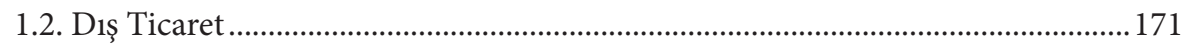

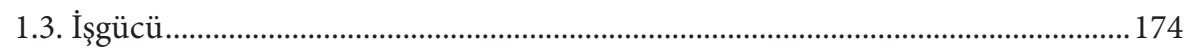

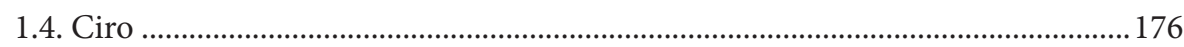

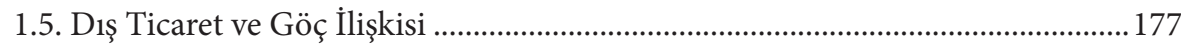

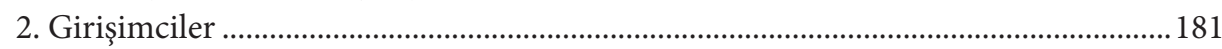

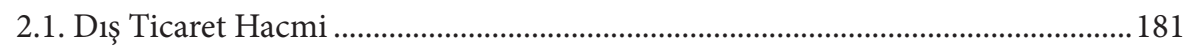

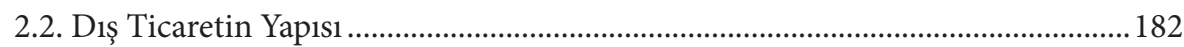

2.3. Dış Ticaret ve Göç İlişkisi .............................................................................................. 185

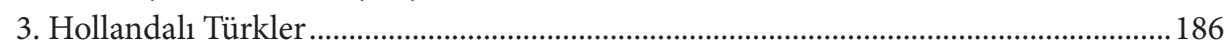

Sonuç ve Değerlendirme ............................................................................... 189

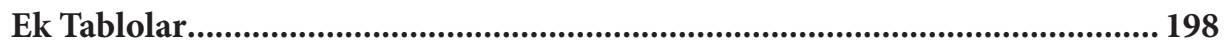

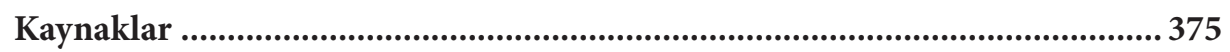


- 


\section{KAYNAKLAR}

CBS. (2018, November 23). Documentatie Hoogst behaald en hoogst gevolgd opleidingsniveau en opleidingsrichting van de bevolking in Nederland (HOOGSTEOPLTAB).

CBS. (2018, March 30). Documentatie Koppeltabel RINPERSOON met BEID voor zelfstandigen (KOPPELTABELZELFSTANDIGEN).

CBS. (2018, December 3). Documentatie Migratiemotieven van immigranten met een buitenlandse nationaliteit (VRLMIGMOTBUS).

CBS. (2018, February 19). Documentatierapport Aangifte Omzetbelasting (BTW).

CBS. (2018, November 7). Documentatierapport Internationale Handel in Goederen (IHG).

CBS. (2019, June 21). Documentatie Banen en lonen op basis van de Polisadministratie (SPOLISBUS). Retrieved from https://www.cbs.nl/nl-nl/onze-diensten/maatwerk-en-microdata/ microdata-zelf-onderzoek-doen/microdatabestanden/spolisbus-banen-en-lonen-volgens-polisadministratie

CBS. (2019, April 25). Documentatie Persoonskenmerken van alle in de Gemeentelijke Basis Administratie (GBA) ingeschreven personen, gecoördineerd (GBAPERSOONTAB).

CBS. (2019, April 1). Documentatierapport Algemeen Bedrijven Register (ABR) $2018 \mathrm{~V} 1$.

de Jong, J. (2011). The Dutch Golden Age and Globalization: History and Heritage, Legacies and Contestations. Macalester Inernational, 27(Article 7). Retrieved from http://digitalcommons. macalester.edu/macintl/vol27/iss $1 / 7$

De Regt, S., Van Duin, D., \& Stoeldraijer, L. (2021, 6 2). Population Forecast 2020-2070: Immigration Assumptions. Retrieved from https://www.cbs.nl/nl-nl/longread/statistische-trends/2021/bevolkingsprognose-2020-2070-veronderstellingen-over-immigratie

IOM. (2019). Glossary on Migration. Geneva: International Organization for Migration. Retrieved 5 25, 2021, from https://www.iom.int/: https://publications.iom.int/system/files/pdf/iml_34_ glossary.pdf

IOM. (2019, 11 5). World Migration Report 2020. Geneva, Switzerland: International Organization for Migration. Retrieved 5 27, 2021, from https://publications.iom.int/books/world-migration-report-2020

Statistics Netherlands. (2012). Baby boomers In the Netherlands: What the Statistics Say. The Hague/Heerlen, The Netherlands. Retrieved Ağustos 16, 2021, from https://www.cbs.nl/en-gb/ publication/2012/17/baby-boomers-in-the-netherlands

Statistics Netherlands. (2016). Annual Report on Integration 2016. The Hague: Statistics Netherlands. Retrieved from https:/www.cbs.nl/en-gb/publication/2016/47/annual-report-onintegration-2016

Van Amersfoort, H., \& Penninx, R. (1994). Regulating Migration in Europe: The Dutch Experience, 1960-92. The Annals of the American Academy of Political and Social Science, 534, 133-146. Retrieved from www.jstor.org/stable/1048504. Accessed 2 Sept. 2021

Van Niekerk, M. (2004). Afro-Caribbeans and Indo-Caribbeans in the Netherlands: Premigration Legacies and Social Mobility. The International Migration Review, 38(1), 158-183. Retrieved from www.jstor.org/stable/27645361

Van Ours, J. C., \& Veenman, J. (2005). The Netherlands: Old Emigrants-Young Immigrant Country. In K. F. Zimmermann, European Migration: What Do We Know? (pp. 173-196). OUP Oxford. Retrieved from https://books.google.com.tr/books?id=ZH7FLD7zfDkC\&$\mathrm{dq}=$ indonesian+immigrants+netherlands\&lr=\&hl=tr\&source=gbs_navlinks_s

Vanneste, A. (2014). The Belgian-Dutch border during the First World War: a second Belgian front? In The Low Countries: arts and society in Flanders and the Netherlands/Stichting Ons Erfdeel [Rekkem]-Rekkem (Vols. 1993-2018, pp. 74-83).

Werner, H. (1994). Regional Economic Integration and Migration: The European Case. The Annals of the American Academy of Political and Social Science, 534, 147-164. Retrieved from www. jstor.org/stable/1048505 